\title{
Sustainable bio-economy that delivers the environment-food-energy-water nexus objectives: the current status in Malaysia
}

\begin{abstract}
Biomass is a promising resource in Malaysia for energy, fuels, and high value-added products. However, regards to biomass value chains, the numerous restrictions and challenges related to the economic and environmental features must be considered. The major concerns regarding the enlargement of biomass plantation is that it requires large amounts of land and environmental resources such as water and soil that arises the danger of creating severe damages to the ecosystem (e.g. deforestation, water pollution, soil depletion etc.). Regarded concerns can be diminished when all aspects associated with palm biomass conversion and utilization linked with environment, food, energy and water (EFEW) nexus to meet the standard requirement and to consider the potential impact on the nexus as a whole. Therefore, it is crucial to understand the detail interactions between all the components in the nexus once intended to look for the best solution to exploit the great potential of biomass. This paper offers an overview regarding the present potential biomass availability for energy production, technology readiness, feasibility study on the techno-economic analyses of the biomass utilization and the impact of this nexus on value chains. The agro-biomass resources potential and land suitability for different crops has been overviewed using satellite imageries and the outcomes of the nexus interactions should be incorporated in developmental policies on biomass. The paper finally discussed an insight of digitization of the agriculture industry as future strategy to modernize agriculture in Malaysia. Hence, this paper provides holistic overview of biomass competitiveness for sustainable bio-economy in Malaysia.
\end{abstract}

Keyword: Biomass; Biomass value chains; Food-energy-water (FEW) nexus; Biomass supply chains; Optimization; Sustainability 